\title{
The Impact of High School Program Reform on First-Year University Students' Academic Performance - Case Study: Biology
}

\author{
Mimoza Milo \\ Agency of Quality Assurance in \\ Pre-university Education, Tirana
}

Anila Paparisto

University of Tirana -HERE

Flamur Bidaj

Polytechnic University of Tirana-HERE

Fatmira Shehu

Agriculture University of Tirana-HERE

\begin{abstract}
The student transition from high school to university is a complex process in which various factors operate. One of these factors is the degree of the students' academic preparation in certain subjects. This article analyzes the impact of this factor on the students' success in the first year of university studies, in the conditions when the subject program in high school has been reformed. This impact on the students' success, which is expressed both in the degree of academic preparation and in the students' attitude in the relevant subject, has been assessed employing statistical analysis. The analysis covers a period of 3 years (2017-2020), and is based on a sample of first year students of the Bachelor degree in Biology. The results of the questionnaire, conducted with first year university students, show the impact of their high school academic preparation on the success they have in the first year of university. This success is measured by assessing the change in average grade and their pass rates. Evidence of the impact of this factor in teaching has helped to know in detail these intermediate phases of this process. The built model makes it possible to analyze the impact of the high school curriculum reform on the students' success, creating the opportunity for further improvements. Despite the fact that the object of the study is the Biology curriculum and the evaluation of the impact in academic success of students who graduated from high schools where a competence based curriculum was implemented, this methodology can be used for the study in other subjects, especially life sciences.
\end{abstract}

Keywords: analysis, impact, reform, Biology, success, student 


\section{Introduction}

To increase student success and further development, Higher Education Institutions draft appropriate policies for student admission. The policy document for admissions is also one of the requirements of standard 1.4. ESG (2015). HEIs must not only have a policy for the admission of their students, but also implement it in a consistent and transparent manner. They should use appropriate and diverse processes and tools to gather information, monitor their admission policies and act on their reformulation based on students' progress data.

Part of the information that HEIs must analyze is the academic preparation of the candidate to enroll in a university study program, especially in the subjects that are part of the admission criteria to this study program.

Numerous studies have found that factors such as high school quality, student motivation, socioeconomic status, university environment, quality of university education, etc., have a significant and direct impact on student success (Van Rooij E ., 2018).

Van Rooij E. (2018), presents this analysis in a synthetic and complete way in "A systematic review of factors related to first-year students' success in higher education", showing the impact of these factors on the average grade, the number of credits and percentage of students continuing their studies after the first year. The list contains 8 factors, which affect these three functions, but which vary depending on the combination of the three indicators for students' success in the first year. Other studies concretely analyze the influence of various factors.

Atuahene and Russell (2016) analyze the impact of Mathematics on the success of first year university students depending on their socioeconomic status and the level of high school. Focusing on high school, Subedi \& Powell (2016) use academic achievement, grade retention as well as demographic and disciplinary factors to predict college readiness in two courses: reading and mathematics. The assessment of college readiness was done using a two-level Hierarchical Generalized Linear Model. They also determined the effect sizes at school level models, based on the sample of 12554 students and 51 high schools in Florida, USA.

The existence of a gap between the subjects developed in high school and at university has been proved by many other studies. Manyatsi, Lubben and Bradley (1999) provided a holistic model of interpreting the gap between secondary education and postsecondary education in Chemistry. Ferna, Gomis and Cid (2002) presented some results of their study for the creation of a bridge between high school and University in the subject of Biochemistry. By adding a course to the high school, it was possible to eliminate the gap between the high school and the university in this course. However, it should be noted that in this case the solution was by increasing student workload in high school.

The existence of a gap and the application of constantly changing curricula in high school necessitate the cooperation between the high school and the University in order to reduce this gap by establishing a more suitable alignment between them. In their study, Neal D. Finkelstein N., D., Becca Klarin B., Marie Olson M., ... (2016), took into account the frequent lack of alignment between high school and college course content and rigor, as well as the lack of sequence of prerequisites. Proving the usefulness of using the alignment of state assessment practices to improve student readiness, they evaluated support initiatives in five action areas: strategic planning, infrastructure, stakeholder engagement, policy and governance, and data and analysis. 
Shelton and Brown (2008) presented the results of measuring the alignment between high school and university in mathematics courses. They measured the degree to which expectations across the secondary and postsecondary education are consistent. The measurements were performed in case the University does not have explicit entrance standards, as it is the Biology case study. In this study they relied on Webb's model, which assesses alignment in four dimensions:

- Categorical concurrence- the same content in both systems

- Depth of knowledge

- Range of knowledge- the range as a person knows a certain subject

- Balance of coverage - degree of realization (coverage) of the course program

While many studies have been conducted in a variety of subjects, the studies in the nature of Mathematics as a subject and the degree of its use continue to be the most frequent regarding the role of academic preparation of the student who enrolls in the first year.

Er (2017) analyzed the academic preparation of first year students and misalignment between students' expectations regarding high school and university, referring to college/university mathematics faculty. Studying high school students' academic preparation in the subject of Mathematics, Blat (2018) identified the key competencies that students should possess when entering the first year of university, also highlighting the growing trend of students who choose an increasing number of mathematics subjects in order to have greater success in their first year of university. Among other things, it is recommended that HEIs should offer supplementary courses in various mathematical subjects, to eliminate the gap that exists between high school and the University. Designing and implementing an appropriate student support strategy is a consistent practice for any HEI. Hodara (2013, p.7) recommended 3 strategies to increase students' success in Mathematics subjects: preparatory courses, improving Mathematics teaching and reforming Mathematics development.

McCormick and Lucas (2011) stressed the importance of appropriate academic preparation in mathematics for both university and the job market, highlighting the role of different schools in the USA.

Academic preparation in Mathematics subjects is important not only for the role it plays in the general preparation of the student, but also for the influence it has on other subjects. Many elements of the completed studies have been used in the study of other subjects, especially those that serve as admission criteria for admission for first year university students.

As Biology is one of the subjects of natural sciences, it goes without saying that the study of high school students' academic preparation has been the focus of many publications, including this article.

Kritzinger, Lemmens and Potieters (2017) have explored the potential of learning analytics for different student groups, applied to a single course, in this case in Molecular and Cell Biology, aiming to use the effective learning strategies, which can serve course designers or curriculum development.

In their study, Kurlaender, Reed and Hurtt (2019) noted that high-achieving students and those who selected the right subjects in high school, had higher scores in both the first year of university and in the labor market, in comparison to others. They stressed the need to choose a rigorous set of courses related to the courses required for admission. The latter requirement 
is very important in admission systems that rely on the grade point average of a group of subjects, as is the case considered in this article.

The success of a student in their first year at university can be determined in different ways. Van der Zanden P., J., A., C. etc (2018) developed a conceptual framework consisting of three domains: students' academic achievement, critical thinking and social emotional wellbeing. In this article, we will rely on the indicator for students' academic achievement, accepting for this purpose two indicators: Average grade and pass rate.

These and other studies show that the grade point average is an indicator to predict or evaluate students' success, of course given the remark made by Atuahene and Russell (2016). They point out that the average grade of high school does not necessarily guarantee the success of the student in the first year of university, especially for certain subjects and in cases of poor socioeconomic status.

The purpose of this article is to analyze and evaluate the impact of college readiness and the relevant reform curriculum on student success in the first year of University. Although the focus of the study is the subject of Biology, the methodology can be used for other subjects that are included in the group of subjects that are part of Admission criteria to a study program.

\section{Survey Methodology and data collection}

This study was extended to three academic years 2017-2018; 2018-2019; 2019-2020. The target group were the first year students of the bachelor study program in Biology. The study was organized in Tirana University, Faculty of Naturel Sciences. Students enrolled at the university in the academic years 2017-2018 and 2018-2019 followed a high school curriculum based on objectives. Those who enrolled at the university in the academic year 2019-2020 during high school had attended the high school curriculum based on learning outcomes and competencies. This is a quantitative study employing a questionnaire to gather data for academic achievement variables. The questionnaire consists of a total of 13 questions about the course sequencing and college readiness. The first year students of the bachelor study program in biology were all invited to complete this questionnaire, just after exams of the first winter semester. The participant students' exam results were provided by the registrar's office, respecting their privacy. The number of students who participated in this study was 100, 100 and 87 respectively for each academic year (2017-2020), which makes up above 90\% of the total number of first year students in this study program.

This study is based on two research questions that focus on the continuity of their knowledge from high school to university. The first research question relates to the students' identification of difficulties in the subject of Biology at university. Meanwhile, the second question focuses on identifying the degree of repetition of knowledge during the development of the biology subject at the university.

The data analysis identified whether there is a correlation between the relative numbers of students who have encountered difficulties or repetition with the relative number of students (x) who have taken the elective course in advanced biology in high school.

These correlations have been used to indicate the continuity of knowledge between secondary and university education.

Using linear regression analysis, two functions are taken to identify the difficulty and repetition that the student encountered in the first year of university. They quantitatively 
express the dependence of each of them on the acquired knowledge in advanced Biology (elective course in high school).

In order to analyze the impact of curricular changes in the subject of Biology in high school, this paper analyzes the student success in the first year of university starting from this perspective as well. For this purpose, two indicators were used: student pass rate and average grade in biology subject at the first year/first semester of university (data provided by the registrar's office respecting privacy and code of ethics). The linear regression analysis method was used in this case as well. The analysis yielded two relevant functions, first between the pass rate and the relative number of students who have taken the elective course in advanced biology and second between average grade in Biology at the university and the relative number of students who have taken the course with in-depth biology choices in high school.

Acknowledging the existence of a linear correlation between the average grade and the relative number of students who have taken the elective course in advanced biology in high school, the theoretical average grade for the relative number of students is calculated. This calculation is realized only for the third year of study (2019-2020), which corresponds to the first generation of students who have completed the reformed curriculum in secondary education. The difference between the theoretical average grade and the real average grade is an indicator that expresses the effect of the reformed curriculum on student success.

The data collected from the questionnaires are presented graphically and analyzed in results and discussion.

\section{Results}

Based on the statistics of academic year 2017-2020, 97.5\% of first year bachelor students in Biology have graduated from general high school.

$40 \%$ of these students say that the elective advanced biology course that they attended in high school has averagely helped them in their success in the first year of university; only 10-15\% of students say that the advanced elective biology course has helped them a lot to achieve good results in the first year of university; about $30 \%$ of students say that this course has helped them a little, while $20 \%$ of them say that they have had no help at all.

From the analysis, it is evident that these percentages do not change (remain more or less of the same values) even for students of the academic year 2019-2020. It is worth mentioning that these students are the first generation who graduated from high schools where a competence-based curriculum was implemented.

The generalized analysis demonstrates that almost half of the students agree that attending the elective advanced biology course is useful for their success in the first year of university, whereas the other half do not agree to that. Some of the reasons which need to be evaluated in other studies might be: the ratio between the core curriculum and the elective advanced curriculum; alignment of core curriculum concepts with elective advanced curriculum concepts; independent student work; teacher work; etc.

In this study we only identify this issue but to give a complete answer a more in-depth study will be needed on this evidence.

By analyzing the answers provided by students for the two research questions, which are placed at the center of this study, based on the percentage of students who say that they have 
encountered difficulties or repetition in the development of biology curriculum at university, we identify the gap between high school and university.

Figure 1 presents the results of the three years of study related to the difficulty indicator. The graph shows the relationship between the difficulty indicator and the relative number of students who have completed the advanced elective biology curriculum in high school. The linear relationship is expressed by this equation:

$y=-0.7873 x+88.513$ where $R^{2}=0.7704$ value, which shows how strong the relationship between these 2 parameters is.

According to the graph, the equation is a decreasing function, as expected.

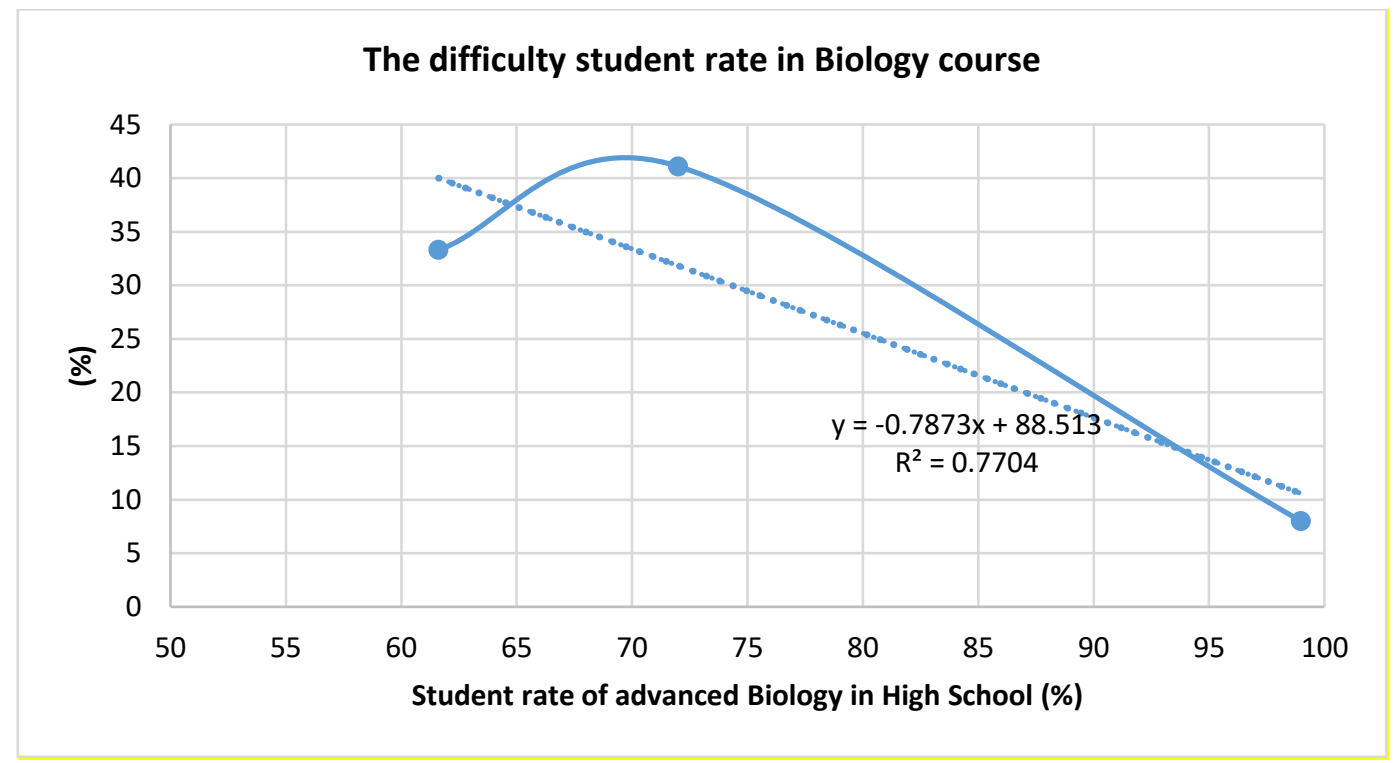

Fig. 1 The change of difficulty rate from student rate of Advanced Biology course in High School

Figure 2 presents the results of the three years of study related to the indicator of repetition (the degree of repetition of concepts in the Biology course which is offered in the first year of university, in relation to the biological concepts obtained in high school). The graph shows the relationship between the repetition indicator and the relative number of students who have completed the course of advanced Biology in high school (marked with $\mathrm{x}$ ). The linear relationship between the parameters is expressed by the equation:

$y=-0.6681 x+85.102$ where the value of $R^{2}=0.7465$ value, which shows how strong the relationship between these 2 parameters is.

As it can be seen from the equation and the graph, this dependence is a falling function. 


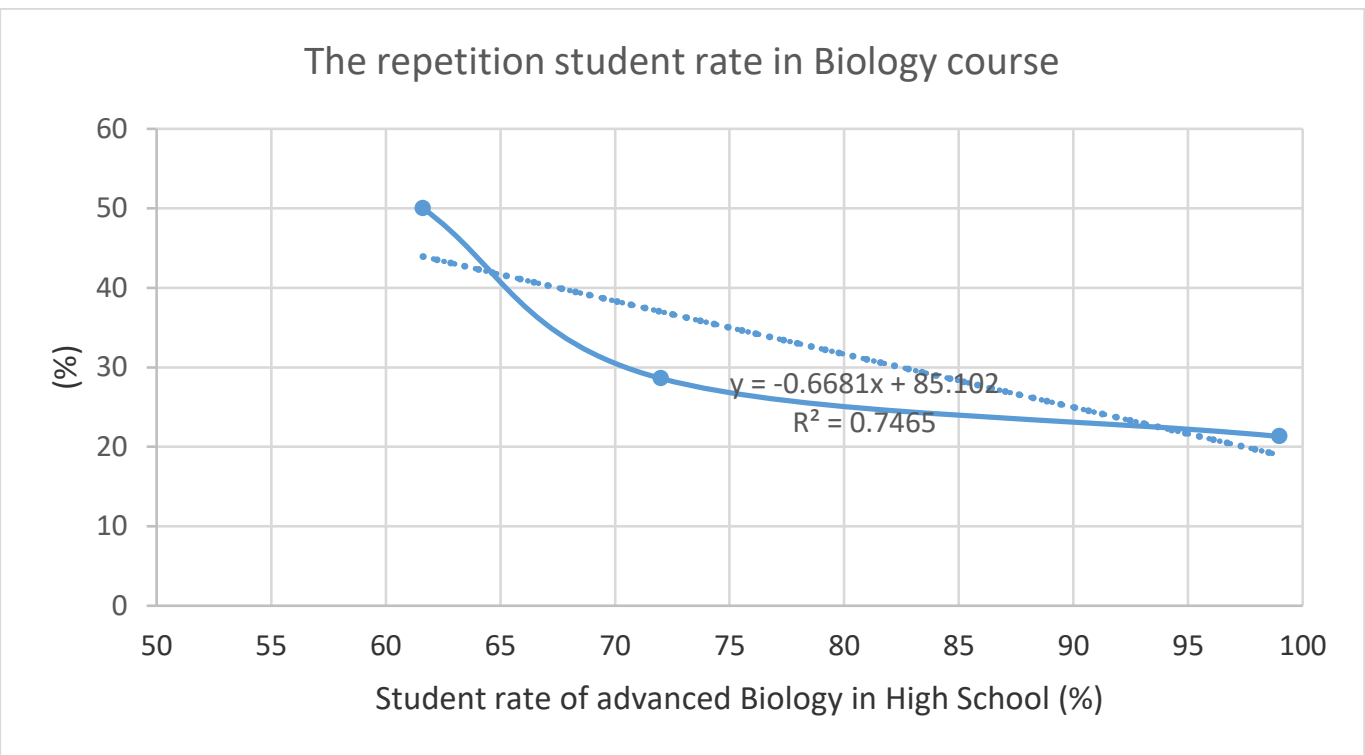

Fig.2 The change of repetition rate from student rate of Advanced Biology course in High School

To assess the impact of curricular linearity and its impact on students' success, the impact of the size $\mathrm{x}$ on the grade and passing averages in the subject of Biology for first year students of the bachelor program has been analyzed.

Figure 3 shows the relationship between the grade average in the subject of Biology in the first year of university and the relative number of students (x) who have taken the subject of advanced Biology in the high school.

The equation $\mathrm{y}=1.8187 \mathrm{x}+4.4599$ and $\mathrm{R}^{2}=1$ is obtained by accepting the linear dependence between the above parameters and it is constructed by being based on the two real values of the average grade of the first two years in the study. This equation gives the expected grade average in the third year of study. This grade average is compared to its real value for the third year of study. The difference between these two values serves as a measure of the impact of the reform in middle education on students' success. 


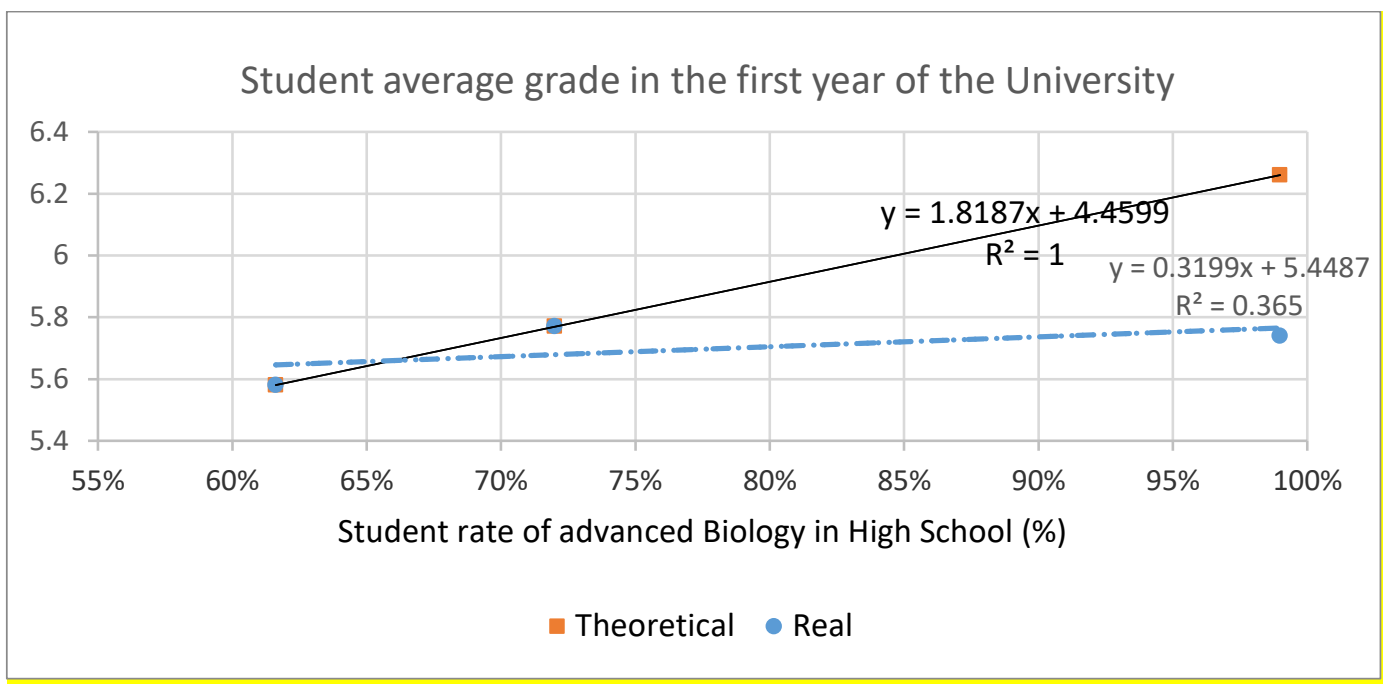

Fig.3 The change of student average grade from student rate of advanced Biology in High School

The average grade in the subject of biology in the third year of study is 5.74, while the expected grade would be 6.26 . The difference between these two values is 0.52 , which shows that in terms of quality, the reform this year has not had a positive impact on students' success. The reasons for this can be many and varied and for their identification a focused study should be undertaken.

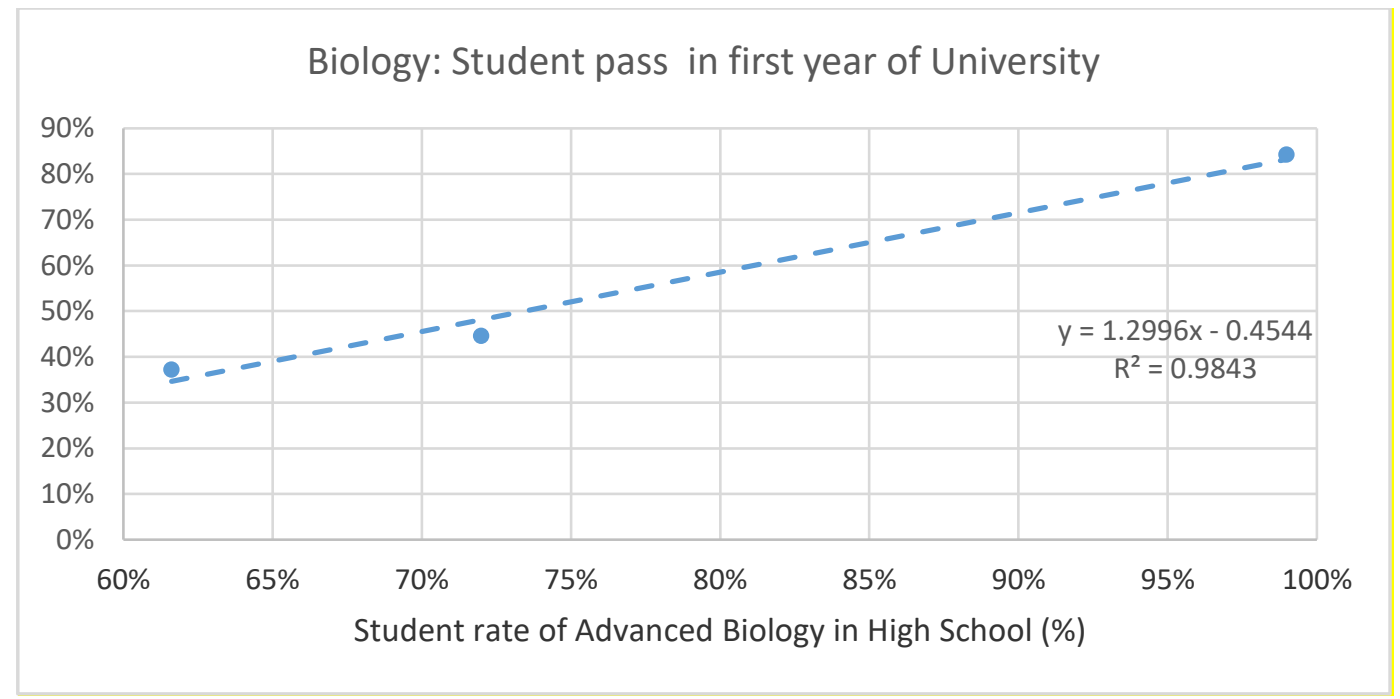

Fig.4 Correlation of student pass rate in first year of University and student rate of advanced Biology course

Figure 4 shows the relationship between passing rate and $\mathrm{x}$. This dependence is linear and is expressed by the equation $y=1.2996 x-0.4544$ and $R^{2}=0.9843$. As it can be seen from the 
graph, the function is increasing, and this shows that the reform has had a positive impact on student success.

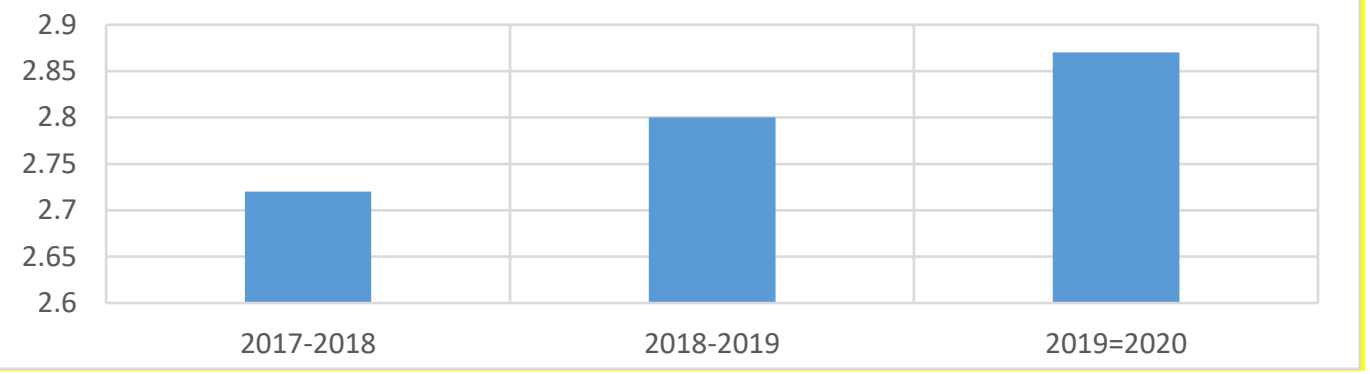

Fig.5 Biology: Student average grade difference between High School and University (20172020).

Figure 5 shows the difference between the high school grade average and the university grade average for Biology. This difference has been constantly increasing, respectively by $2.72 ; 2.8$; 2.87. These values indicate that there is a gap between the two systems, which does not support the student in his/her success.

\section{Discussions}

The academic preparation of the student in high school affects the success of the first year student in the university and beyond. As evidenced by the results of this study, this impact is not uniform across the student population.

From the graphic representations in Figures 1 and 2, the degree of academic preparation with which students come from high school to university, expressed in the relative number of students who have completed the Advanced Biology course, affects both the degree of difficulty and the degree of repetition in the subject of biology developed during the first year of university studies in the bachelor program.

Note that this effect is different and can be estimated through the respective angular correlation coefficients $(\mathrm{k}=0.787)$ and $(\mathrm{k}=0.668)$.

From the results obtained, it seems that the degree of academic preparation has a greater impact on the degree of difficulty that students encounter during the development of the university curriculum in biology.

The lower the level of academic preparation that students have from high school, which in this study is measured by the percentage of students who have developed the subject of advanced biology, the greater the degree of difficulty that students identify in the development of biology subject at university.

This correlation should be taken into account by the lecturers of the subject and other university structures responsible for improving the quality of teaching and eliminating the gap between the high school and the university.

The analysis of the impact of student academic preparation on the formatting of the university learning process also focuses on student success indicators. 
These indicators are also influenced by an additional factor, that of the reform of the Biology course program in the High School as a result of the reform in pre-university education.

As indicators of student success are accepted the average grade and the passing rate, which are taken in the analysis for the subject of biology in the first year of university.

From the results obtained and presented graphically in Figures 3 and 4, it seems that the higher the number of students who have completed the course of Advanced Biology in secondary education, the higher the average grade and passing rate.

The passing rate has reached the value of $84 \%$, when a year ago it was $45 \%$, referring to a relative number of students who have completed the course of Advanced Biology with an increase of $72 \%$.

In terms of average grade indicator, there is an increase in the second year of study (20182019) compared to the previous year, but it remains almost constant in the third year (20192020), which is also the first year of reform of the Biology Course Program in the High School.

In fact, in the last year of this study, $100 \%$ of the students enrolled in the first year of university studies in the bachelor biology program have completed the Advanced Biology course in high school, so referring to the linear correlation, the expectation should give an average grade of 6.26, when in fact it results 5.77 .

Implementation of curriculum based on learning outcomes and competencies is also associated with problems, which apparently have had a different impact on student success indicators in the first year.

Thus, if the passing rate has increased, that of the average grade, due to the reform, turns out to have decreased.

In fact, the grade point average is influenced by the relative number of students who have completed Advanced Biology, as well as the reform of High School curriculum.

While the first factor gives a positive impact on the average grade of students, the second factor has resulted in a negative impact on student success.

This change, which is $9 \%$ in relative size, shows the negative impact that the problems encountered in the implementation of the new curriculum have had, which have often led to incomplete and / or qualitative non-implementation of the reformed program.

This means that measures should be taken in the High School for further improvements of the realization not only in terms of quantity, but also the quality of the reformed curriculum in all subjects, including the subject of biology.

To better understand the improved delivery quality of the reformed high school curriculum, monitoring of this indicator can also be used.

This monitoring and verification process includes the indicator of the difference of the average grade between the high school and the University.

The increase of $2.5 \%$ of this difference in the year of the reform (2019-2020) is not a consequence of the success of the student in the university, but of the evaluation system in the High School. 


\section{Conclusions}

Academic preparation in High School affects the level of knowledge provided by the academic staff in the first year university courses and the skills they expect students to develop, as part of their effort to offer instruction that both complements the learning outcomes of the bachelor program, and gives all students the opportunity to be involved in the process.

This impact on teaching is different, it is more noticeable in the degree of difficulty faced by students $(\mathrm{k}=0.778)$, versus the degree of repetition developed at the University $(\mathrm{k}=0.668)$.

The academic preparation of high school students also affects student success, which is namely assessed through the two linear functions of grade average and pass rate.

The difference of $2.5 \%$ between High school average grade and University average grade in the subject of Biology is the impact of the evaluation system in the High School and not the success of the student in the subject of Biology at the University.

\section{Bibliography}

[1] Atuahene, F., \& Russell, T. A. (2016). Mathematics readiness of first-year university students. Journal of developmental education, 12-32.

[2] Blat, C. E. (2018). Mathematics Readiness of Entering College Students (Doctoral dissertation, The University of North Carolina at Charlotte).

[3] Er, S. N. (2018). Mathematics readiness of first-year college students and missing necessary skills: perspectives of mathematics faculty. Journal of Further and Higher Education, 42(7), 937-952.

[4] European Association for Quality Assurance in Higher Education (ENQA). (2015). Standards and guidelines for quality assurance in the European Higher Education Area (ESG).

[5] Fernàndez-Novell, J. M., Gomis, R. R., Cid, E., Barberà, A., \& Guinovart, J. J. (2002). Bridging the gap in biochemistry between secondary school and university. Biochemistry and Molecular Biology Education, 30(3), 172-174.

[6] Finkelstein, N. D., Klarin, B., Olson, M., Austin, K., Dadgar, M., Mundry, S., \& Bugler, D. (2013).Implementing the common core state standards: Articulating course sequences across $\mathrm{k}-12$ and higher education systems.

[7] From the Department of Biochemistry and Molecular Biology, University of Barcelona, Barcelona E-08028, Spain

[8] Hodara, M. (2013). Improving students' college math readiness: A review of the evidence on postsecondary interventions and reforms.

[9] Josep M. Ferna` ndez-Novell‡, Roger R. Gomis, Emili Cid, Albert Barbera`, and Joan J. Guinovart, From the Department of Biochemistry and Molecular Biology, University of Barcelona, Barcelona E-08028, Spain

[10] Josep M. Ferna`ndez-Novellキ, Roger R. Gomis, Emili Cid, Albert Barbera`, and Joan J. Guinovart

[11] Kritzinger, A., Lemmens, J. C., \& Potgieter, M. (2018). Learning strategies for first-year biology: Toward moving the "Murky Middle". CBE-Life Sciences Education, 17(3), ar42.

[12] Kurlaender, M., Reed, S., \& Hurtt, A. (2019). Improving college readiness: A research summary and implications for practice. 
[13] McCormick, N. J., \& Lucas, M. S. (2011). Exploring mathematics college readiness in the United States. Current Issues in Education, 14(1).

[14] Rollnick, M., Manyatsi, S., Lubben, F., \& Bradley, J. (1998). A model for studying gaps in education: A Swaziland case study in the learning of science. International journal of educational development, 18(6), 453-465.

[15] Shelton, A. R., \& Brown, R. S. (2010). Measuring the alignment of high school and community college math assessments. Journal of Applied Research in the Community College, 18(1), 1-10..

[16] Subedi, B. R., \& Powell, R. (2016). Factors influencing college readiness: A multilevel study to measure school effects. International Journal of Learning, Teaching and Educational Research, 15(11), 71-86.

[17] van der Zanden, P. J., Denessen, E., Cillessen, A. H., \& Meijer, P. C. (2018). Domains and predictors of first-year student success: A systematic review. Educational Research Review, 23, 57-77.

[18] Van Rooij, E. (2018). Secondary school students' university readiness and their transition to university.

Web

[1] https://files.eric.ed.gov/fulltext/EJ1130188.pdf

[2] https://educationnorthwest.org/sites/default/files/resources/improving\%20colleg e\%20math\%20readiness_0.pdf

[3] https://www.elsevier.com/locate/edurev

[4] https://edpolicyinca.org/sites/default/files/R_Kurlaender_Aug19. pdf

[5] http://cie.asu.edu/ojs/index.php/cieatasu/article/view/680

[6] https://www.wested.org/wpcontent/uploads/2016/11/1379447958C2C_Impleme nting_Common_Core_State_Standards-3.pdf 